https://doi.org/10.48009/1_iis_2006_13-17

\title{
A FRAMEWORK FOR AN ETHICS COURSE FOR THE INFORMATION TECHNOLOGY STUDENT
}

\author{
Dr. Cecil Schmidt, Computer Information Sciences, Washburn University cecil.schmidt@ washburn.edu \\ Dr. Robert J. Boncella, School of Business, Washburn University, bob.boncella@washburn.edu
}

\begin{abstract}
Social and ethical issues have and will continue to confront information technology professionals. As such, both the Association of Computing Machinery and Institute of Electrical and Electronics Engineers, Inc. organizations have emphasized the necessity for coverage of ethical issues in computing sciences curricula. This paper provides a detailed framework for a computer information science course that addresses these social and ethical issues. This framework includes a weekly plan, student assessment alternatives, suggested reading alternatives, learner outcomes, and the guiding foundations for this course.
\end{abstract}

Keywords: Computer Ethics, Computer Ethics Curriculum, Computer Ethics Course

\section{INTRODUCTION}

Social and ethical issues have and will continue to confront information technology professionals. Understanding this need, most computer science educators agree that some form of information technology ethics should be taught at the undergraduate level Ethics instruction should be grounded in a social context of the typical ethical dilemmas one faces in using and creating technology. The social impact of innovations and implementations of technology cannot be underestimated. Accordingly, both the ACM and IEEE organizations have strongly suggested that a minimum of 16 core hours of computer science or information technology instruction should be devoted to social and professional issues including ethics [2].

Information Technology is more than just making cool programs [5]. Students should become aware of the effect their work may have on society. Morris [6] suggests that in order to understand the social and ethical issues of computer science (or information technology) one must study the science of computing and not just programming.

Information technology students will be faced with many ethical decisions throughout their careers. These issues can arise in many different forms. For example within the job of network support, a network administrator may be asked to implement email filters. McKenzie [4] identifies some of the potential issues that might arise within this task. For example, a network administrator has tremendous power that is often unrealized by her or his management. Policies are often up for interpretation and the network administrator is often allowed to perform this interpretation. Implementing the correct amount of filtering requires more than just technical knowledge. It also requires an understanding of the social and ethical implications that arise when applying these filters. In general, IT graduates need to be able to identify the related social and ethical issues to a problem such as this and other problems.

Not only do we need a course in information technology and ethics, but we need to integrate an awareness of ethical issues related to IT into our programs of study. Ideally, social and ethical issues relating to IT should be introduced early on and reinforced throughout the program in subsequent information technology courses. Martin and Holz [3] provide a detailed proposal on such an implementation. This is the ideal situation. It is a fact that that most if not all IT curricula are a constraint satisfaction problem. The constraints are the student's need to satisfy university requirements, (e.g., English composition, etc.), School requirements, (e.g., AACSB core courses), and finally the courses required for a major field of study. All these need to be taken within a minimum total number of credit hours. The end result is that the number courses required for the major are restricted, and each course is completely devoted to the core topics of study. As a result there is very little slack time in any course in which to focus on the social and ethical issues associated with the topics of that course. Further, most first year students have yet to acquire the in depth understanding of how IT "fits together." In addition, they may be somewhat underdeveloped in their critical thinking abilities. This is what a university education is supposed to enhance-critical thinking.

Given the facts of limited time in IT courses and limited critical thinking skills of first-year students, it is apparent that the most effective way of conducting 
instruction in the field of IT and Ethics is to offer a course that is taken in the senior year. This course will have a closure aspect with regard to IT topics but would contain an introductory study of formal ethical theories. In this way students will have the subject matter expertise in IT upon which they can apply the moral principles supplied by various ethical theories.

\section{LEARNER OUTCOMES}

A student needs to acquire the skills to be able to make a value-based decision on a social and ethical problem related to technology. In order to do this, the student must demonstrate the following:

- Knowledge of different theories of ethical decision making so that they may be able to evaluate complex issues and logically defend their decisions.

- The ability to identify and distinguish among the various ethical theories so that they may apply these appropriately in analyzing moral problems associated with information technology.

- The understanding that technology is morally neutral

- The ability to identify and articulate the inadequacy of an ethical theory in a particular circumstance; that is, the ethical dilemmas that may arise when applying a particular ethical theory to a particular moral problem.

- Demonstrate the use of and the application of the ethical theories in of the following areas: copyright and fair use, privacy, forbidden knowledge, computer risks and responsibilities, ethical issues related to artificial intelligence, data mining, education, medical technology, ethics in the work place, and future technology.

\section{COURSE OUTLINE}

The following course outline assumes that the course contains students that have senior standing, will be offered in either a fall or spring semester typically spanning 15 weeks of instruction, and that each week consist of three 50-minute class periods. The outline consists of the week number, the primary topic, and a brief description of the content covered. For each topic covered, typically two or three class periods will be devoted to lecture and discussion, one class period will be devoted to reading and writing, and a final class period will be devoted to discussion of the cases or problems assigned.

Weeks 1 and 2: Overview of Technological Change, History of Computing, Networking, Information systems, some moral problems caused by technology.
The intent of this week is to set the stage for a presentation of ethical theories and how they maybe used to decide moral problems caused by information technology.

Weeks 3 and 4: Theories of Ethical Decision Making. Theories to be presented and discussed are Subjective Relativism, Cultural Relativism, Divine Command Theory, Kantianism, Act Utilitarianism, Rule Utilitarianism, \& Social Contract Theory. It will be argued that only the ethical theories of Kantianism (KANT), Act Utilitarianism (AU), Rule Utilitarianism (RU), \& Social Contract Theory (SCT) are adequate for analyzing the moral problems that are created by the use of information technology. It will be emphasized that technology is morally neutral in these moral problems.

Week 5 \& 6: Moral Problems When Using the Internet (MP-INET). Among the problems presented and analyzed are spam, easy access to pornography, censorship, and free speech.

Week 7 \& 8: Moral Problems Associated with Intellectual Property Rights and Information Technology (MP-IPR). Among the problems presented and discussed are as follows: What is intellectual property? How does information technology infringe on these rights. What is fair use? What is the effect of peer-to-peer network? What moral problems do they cause?

Week 9 \& 10: Moral Problems Associated with Personal Privacy and Information Technology (MPPRIV). Among the problems presented and discussed are: What is privacy? Do we have a natural right to privacy? How does information technology effect privacy? To what moral problems does this lead? How can they be resolved?

Week 11 \& 12: Moral Problems Associated with Computer and Network Security (MP-SEC). Among the problems presented and discussed are: What are viruses and Trojan Horses? Also what are the morality issues associated with hacking, denial of service attacks, Trojan Horses, and viruses and how are they decided?

Week 13: Moral Problems Associated with Computer \& Software Reliability (MP-SFTWR). Among the problems presented and discussed are how is liability determined when computer hardware and software fails?

Week 14: Moral Problems Associated with Information Technology in the Workplace (MP- 
WRK). Among the problems presented and discussed are What is the "digital divide?" Should it be resolved? Can it be resolved? What are employer obligations with regard to disintermediation, safe human computer interfaces on the job? What are the effects of work place computer monitoring?

Week 15: IT as a Profession - What Are the Ethical Requirements? (MP-IT-Prof). Examine and discuss professional codes of ethics. Are they fair? Are they effective?

\section{STUDENT ASSESSMENT}

After each topic has been lectured on and discussed, the students will be assigned a number of questions. These questions will be a combination of two types. The majority of questions will be a straight forward review of material type question. The second type of question will be a discussion type question where the student will have to apply ethical theories to moral problems that arise because of information technology. For both types of questions, the student will have to prepare written responses. This will be done by giving the students a class period to work on their responses. They will be encouraged to consult with their fellow students in preparing their responses. The next class period will be used by the students to present their responses to the discussion type questions. The instructor will moderate and facilitate this discussion. A student will be evaluated on their responses to the factual questions for review type questions and on how well they respond to the discussion type questions.

Evaluation of the review type questions is simple since these questions are objective - multiple choice, short answer, and fill-the-blank. The responses will be correct or incorrect. The discussion questions are open-ended and require a more sophisticated evaluation method. Since these questions will be, in essence, moral reasoning questions, it is appropriate that an evaluation rubric be devised that relies on Kohlberg's Theory of Moral Development [1].

Specifically, a response to a discussion question will be judged as to what stage (pre-conventional, conventional, or post-conventional) of reasoning is used in resolving a particular moral problem. And further, what level within each stage has been used as well. Each discussion question will be assigned a score of 1 to 6 where the score denotes the level/stage of moral reasoning defined in the Kohlberg classification. These are listed in Table 1.

Table 1. Kohlberg Classification Levels and Stages of Social Orientation

\begin{tabular}{llll}
\hline Level & Stage & Social Orientation & Justification Stem \\
\hline Pre-conventional & 1 & Obedience/Punishment & "You could get into trouble" \\
Conventional & 2 & $\begin{array}{l}\text { Reward Oriented } \\
\text { Good-boy/Good-girl }\end{array}$ & $\begin{array}{l}\text { Law and Order } \\
\text { Social Contract }\end{array}$ \\
Post-conventional & 3 & "It would disappoint ..." \\
"It is your duty to do ..." \\
"Others would be harmed if..." \\
"Others would benefit if ..." \\
"I believe it is the right thing to do \\
because it is a good thing in itself" \\
should not take advantage of
\end{tabular}

The justification stem is provided to help evaluate the level/stage of moral reasoning being used to justify a moral judgment. It is hoped that by the end of the course, a ranking of level/stage five (postconventional social contract) reasoning will be the main reasoning method for the students.

\section{GUIDING THEORY FOR INSTRUCTION}

Students need to construct their understanding of the course material based on guidance from the instructor as well as from the instructional content. Computer ethics is an ill-structured and complex domain. This domain is one that is best learned though the use of cases with deep narrative discussions. The grounding learning theory for this course is Cognitive Flexibility Theory (CFT) which was initially described in a technical report in [8] and further detailed in subsequent research in [9]. The central claim of CFT is the avoidance of inappropriate over-simplification of content will improve learning and the transfer of complex knowledge. One of the suggestions of CFT 
is to emphasize a crisscrossing of the complex material. As such, the application of the ethical theories crossing multiple cases in different moral problem areas in technology should improve student learning over this domain (see Figure 1).

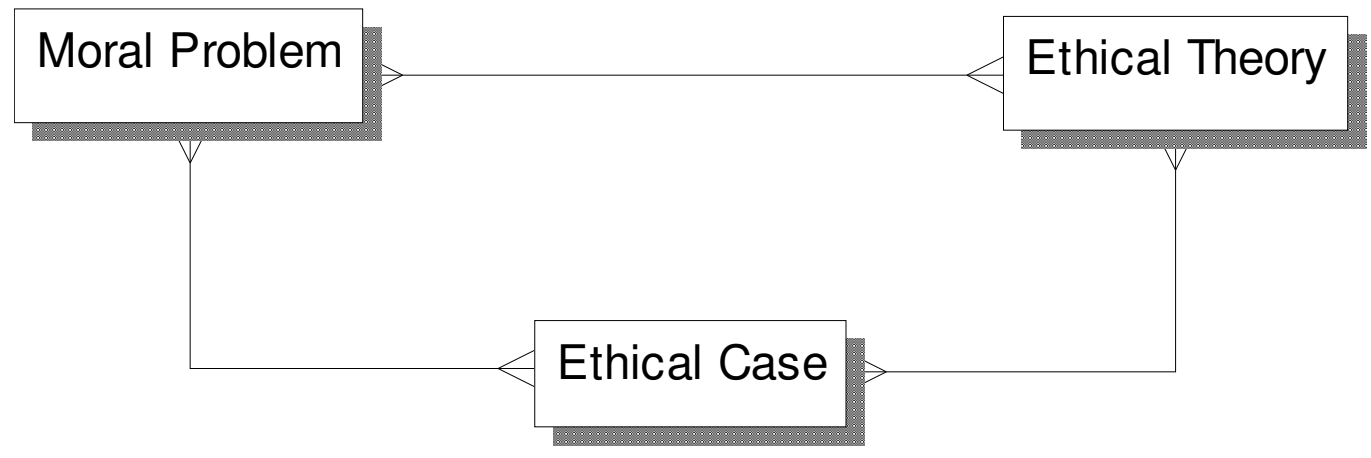

Figure 1. Relational Model of Ethics Course Content Coverage Illustrating Use of CFT

Notice that in Figure 1, each ethical theory listed in Table 2 (column headings) can be applied to one or more of the moral problems listed in Table 2 (cells). Additionally an ethical theory can be associated with more than one moral problem. Finally we can apply more than one ethical theory to each of the cases. The rows of Table 2 illustrate the instructional sequence we will use in order to incorporate the use of CFT.

Table 2. Application of Ethical Theories to Moral Problems Matrix (See Course Outline section for abbreviations)

\begin{tabular}{lllll}
\hline Weeks & Coverage & & \\
\cline { 2 - 5 } Iheory & KANT & AU & RU & SCT \\
\hline \hline $5 \& 6$ & MP-INET & MP-INET & MP-INET & MP-INET \\
$7 \& 8$ & MP-IPR & MP-IPR & MP-IPR & MP-IPR \\
$9 \& 10$ & MP-PRIV & MP-PRIV & MP-PRIV & MP-PRIV \\
$11 \& 12$ & MP-SEC & MP-SEC & MP-SEC & MP-SEC \\
13 & MP-SFTWR & MP-SFTWR & MP-SFTWR & MP-SFTWR \\
14 & MP-WRK & MP-WRK & MP-WRK & MP-WRK \\
15 & MP-IT-PROF & MP-IT-PROF & MP-IT-PROF & MP-IT-PROF \\
\hline
\end{tabular}

Note. Coverage refers to the application of ethical theories on the moral problems. For example during weeks $5 \& 6$, MP-INET, i.e., Moral Problems When Using the Internet will be discussed in terms of each of the ethical theories.

Incorporating cases that have already been analyzed by an expert as well as requiring the student to construct their own analysis is also a sound application of constructivist learning. Linking the theories, problems, and cases should also aid the learner in their ability to see patterns in how the moral problems can be analyzed and resolved. Using cases to illustrate the patterns and the complexities of ill-structured domains is also emphasized by CFT.

\section{AUTHORITATIVE TEXTS AND MATERIALS}

An ethics course like this may be taught through a diverse set of readings and not necessarily from a single textbook However a recent textbook by Michael Quinn [7] does an excellent job of presenting ethical theories in a way that is accessible for a student of information technology. In addition, he organizes the moral problems associated with 
information technology in a natural way based on the individual's use of information technology. He considers the ethical judgments that a person has to make ranging from the highly personal use of the Internet to the remote perspective of IT in the working place. With each of these, he demonstrates how ethical theories are used to resolve these moral problems. It is this technique that is desirable for a student to learn.

\section{CONCLUDING REMARKS}

Social and ethical issues will continue to confront information technology professionals and thus must be addressed as part of the education of computer and information sciences. Providing a capstone type course in the social and ethical issues of computer technology meets the computer science curriculum requirements established by the ACM and IEEE organizations. More importantly, this course will help any student that is faced with an ethical dilemma related to information technology make informed decisions.

Instructional content for computer ethics should initially include significant discussion of ethical precepts and professional codes of conduct. Following the discussion of these precepts and codes, a substantial number of cases should be provided with alternative points of view supporting the learner in their understanding of how these precepts and codes apply. Having access to an authoritative text, a reading list of peer reviewed papers, cases with alternative views, and guided instruction, students are provided the necessary scaffolding for their learning and meaning making. Thus the goals and learner outcomes for this course are realized.

The course design described in this paper has tremendous potential within the curriculum of a liberal arts education. A computer ethics course could easily be classified as one that meets the requirements for general education. The potential to attract students who are outside of the computer and information science majors has compelling implications. These implications include the ability to enhance the offerings for a liberal arts education and potentially provide a course for graduate credit that is multi-disciplinary in nature. Finally, a course dealing with the social and ethical issues of computing fills a need and a demand that will be levied on all professionals who are associated with information technology.

\section{REFERENCES}

1. Barger, R. N. (2000). A Summary of Lawrence Kohlberg's Stages of Moral Development. http://www.nd.edu/ rbarger/hohlberg.html.

2. Engel, G. \& E. Roberts (Eds). (2001). Computing Curricula 2001 - Computer Science, IEEE Computer Society and Association for Computing Machinery. Retrieved October 21, 2002

from http://www.computer.org/education/cc2001/final /cc2001.pdf

3. Martin, D. \& Holz, H. (2003) Non-apologetic computer ethics education: A strategy for integrating social impact and ethics into the computer science curriculum. Retrieved October 25, 2004, from http://www.southernct.edu/organizations/rccs/res ources/teaching/teaching_mono/martin_holz/mar tin_holz_analysis.html

4. McKenzie, J. (1996). A dozen reasons why schools should avoid filtering. From Now On, The Educational Technology Journal. Retrieved February 12, 2003, from http://www.fno.org/mar96/whynot.html

5. Medley, M.D., Rutherford, R., Anderson, G.E., Roth, R.W. \& Varden, S. (1998) Ethical issues related to internet development and research, ITICSE' 98

6. Morris. J. (2004) Programming doesn't begin to define computer science. Post-Gazette.com, July 4, 2004

7. Quinn, M. J.(2006). Ethics for the Information Age $2^{\text {nd }}$ ed., Boston, MA: Pearson Education.

8. Spiro, R. J., Coulson, R. L., Feltovich, P. J., \& Anderson, D. K. (1988). Cognitive flexibility theory: Advanced knowledge acquisition in illstructured domains. (Technical Report No. 441). Champaign, Illinois: University of Illinois at Urbana-Champaign.

9. Spiro, R. J., Feltovich, R. P., Jacobson, M. J., \& Coulson, R. L. (1992). Cognitive flexibility, constructivism, and hypertext: Random access instruction for advanced knowledge acquisition in ill-structured domains. In T. M. Duffy, \& D. H. Jonassen (Eds.), Constructivism and the technology of instruction: A conversation (5776). Hillsdale, NJ: Erlbaum. 